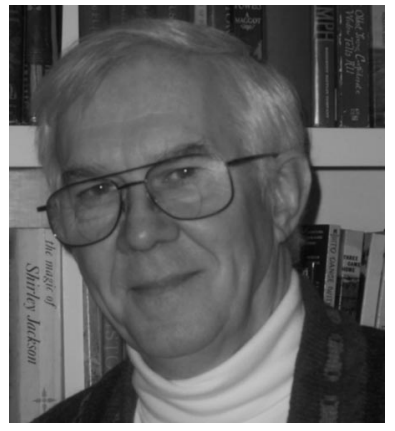

\section{Keeping Old Texts Alive}

At the beginning of January I was working in my office at Georgia Tech when a student poked his head in my office and asked if I was who the sign on the door said I was.

"Yes?" I replied.

“Good. If I get my laser textbook, will you sign it?" he asked.

"Sure." And he was gone. He reappeared a few minutes later with a copy of Introduction to Lasers and Their Applications in hand. I am always flattered when someone asks me to sign their book. But I was brought up a bit short when the student informed me, without a trace of sarcasm or irony, that he thought it was only right to ask for a signed copy since it cost $\$ 140$.

A hundred and forty dollars! My hand paused above the page. The cover of the book I was about to sign did not sport the black, white, and He-Ne red design that my co-authors, Bill Rhodes and Russ Callen, and I had decided upon after much discussion. Instead there was a drab, dark blue cover with the title and our names in a large Times typeface. The pages of the text were printed on demand from poorly scanned images from the original text. And these pages were not enclosed in some special leather-bound binding, let alone the standard hard covers that had been used originally. Instead it was a paperback book with a conventional "perfect" binding.

I signed the title page and returned it to the student with an apology for the cost. He brushed off my apology as not required. Apparently, that's the way it is for textbooks these days.

Maybe so. But from my point of view, our book was overtaken by steady progress in laser technology. At one time, it served as a useful introduction to lasers for undergraduate students. Over the years, salesmen for laser companies told me that the book was their first introduction to lasers and it helped them find their bearings when they entered the field. I think the introductory material holds up fairly well, but the descriptions of the lasers and the applications betray it as seriously out of date. There is a rather fulsome description of gas lasers, some of which, like the helium-selenium laser, have become technological relics. The diode lasers discussion gives no hints of the bright possibilities that allow them to replace many of the gas lasers and laser flash lamps. We were able to sneak in a short discussion of the excimer laser before the book went to press. But that's as current as it got. Yet, it is still being used as a class text.

Now that I am sitting on the sidelines, I think that few students, even at the master's level, need an in-depth knowledge of the physics of most lasing systems. Rather, they need information that provides sufficient insight into the operating characteristics, output manipulation, and common applications of the lasers that they will use in their research and development work.

A few weeks before this, my son, Patrick, agreed to teach a course on lasers at Fort Belvoir as part of an on-base education sequence offered by George Mason University. We discussed our laser text and agreed that there were better texts to be had. After a survey of the current offerings, he chose Verdeyan's Laser Electronics (Prentice-Hall, 1985) because it had a better engineering approach after considering Svelto's Principles of Lasers (Plenum, 2004), which is very strong on the physics of lasers.

Although my co-authors and I consider our text to be a dinosaur, it is still being sold by Pearson Education, which acquired the rights when it bought Addison-Wesley several years ago. I went to the Pearson web site and after a diligent search, I found the text (illustrated with the original cover), now priced at $\$ 163$ ! In the space of two months the price of our text has jumped by $12 \%$. Wow!

But why would a nearly obsolete text that did not change in any way be worth more after two additional months of aging? It can't be storage costs because the text is printed on demand. It gives one pause to know that your publisher has just increased the price an additional $\$ 18$ for a laser text that is 28 years old.

Not so long ago, when a book was judged to be obsolete, it was dropped from the publisher's backlist and, in most cases, the rights reverted to the authors. Now, by providing a form of life support by printing on demand and by listing on Amazon.com, a publisher can extend the life of a text beyond its natural span, making it available to those poor souls that don't know any better or who are assigned it for class.
Donald C. O'Shea Editor 